\title{
Lymphocyte proliferation to artery antigen as a positive diagnostic test in polymyalgia rheumatica
}

\author{
B. L. HAZLEMAN, I. C. M. MACLENNAN, AND M. M. ESIRI \\ From Nuffield Orthopaedic Centre and Nuffield Department of Medicine, Radcliffe Infirmary, Oxford
}

\begin{abstract}
Hazleman, B. L., MacLennan, I. C. M., and Esiri, M. M. (1975). Annals of the Rheumatic Diseases, 34, 122. Lymphocyte proliferation to artery antigen as a positive diagnostic test in polymyalgia rheumatica. The transformation response of peripheral blood lymphocytes in vitro to human arterial and muscle antigen has been studied in patients with polymyalgia rheumatica, polymyositis, rheumatoid arthritis, and polyarteritis nodosa and in unrelated controls. Lymphocytes from patients with polymyalgia rheumatica showed transformation responses significantly higher to artery antigen than those in the other disease and control groups. The highest responses were found in patients with evidence of the most active clinical disease at the time of testing. It is suggested that the transformation response to arterial antigen might aid the diagnosis of polymyalgia rheumatica.
\end{abstract}

Polymyalgia rheumatica is a clinical syndrome in which severe pain and stiffness of the muscles of the shoulder and pelvic girdles are the main features. It is of unknown aetiology, and diagnosis is made by exclusion of the other disease states, there being no one test which is specific to the disease.

In many patients with polymyalgia rheumatica, an underlying vasculitis can be shown. Hunder, Disney, and Ward (1969) reported on 356 patients, of whom 167 had a temporal artery biopsy. Arteritis was found in 84. Alestig and Barr (1963) reported positive temporal artery biopsies in patients with myalgia but without local symptoms in the temporal region; and Fauchald, Rygvold, and Oystese (1972) found 20 positive arterial biopsies in 49 patients with myalgia alone. These authors found it difficult to make any clinical distinction between the two disorders. The vasculitis is widespread (Hunder and Sheps, 1967; Andrews, 1966) and vascular tenderness and bruits may be detected over major arteries (Hamrin, Jonsson, and Landberg, 1965; Bruk, 1967).

There is little evidence to support a concept of primary muscle disease. Serum aldolase and creatine phosphokinase are normal and there is no abnormality on electromyography (Chalmers, Alexander, and Duthie, 1964; Bruk, 1967). Muscle biopsy has shown only atrophic changes and there is no evidence of muscle fibre destruction (Hamilton, Shelley, and Tumulty, 1971; Brooke and Kaplan, 1972). There appears to be no overall difference in the disease or its course in those with or without positive biopsies (Fauchald and others, 1972) and a widespread vasculitis would explain the features of the disease.

An increased rate of lymphocyte transformation $\stackrel{\mathbb{Q}}{\perp}$ in the presence of muscle was shown in lymphocytes $\vec{F}$ from patients with polymyalgia rheumatica (Esiri, 응 MacLennan, and Hazleman, 1973) and polymyositis (Saunders, Knowles, and Currie, 1969; Esiri and others, 1973). In polymyositis it has been suggested that muscle fibre destruction is associated with, and $\overline{0}$ might be caused by, an increased sensitivity to muscle 윽 antigens. In polymyalgia rheumatica, it was suggested that the sensitizing antigen may reside in the vascular or connective tissue inevitably present in the skeletal muscle homogenate.

The purpose of the present study was to confirm $D$ that peripheral blood lymphocytes from patients with polymyalgia did have an increased rate of $N$ DNA synthesis in 5-day cultures set up in the presence of muscle and, at the same time, examine the response $\triangle$ to arterial homogenate. Patients with polymyositis, rheumatoid arthritis, and polyarteritis nodosa were $\bar{Q}$ also studied. The method used was to assess the rate 0 of tritiated thymidine incorporation into DNA as a measure of the proliferative response to antigen.

\section{Materials and methods}

PATIENTS

A summary of the patients studied is shown in Table I. A total of twenty patients with polymyalgia rheumatica $?$ 
Table I Details of patients with polymyalgia rheumatica and rheumatoid arthritis

\begin{tabular}{|c|c|c|}
\hline & $\begin{array}{l}\text { Patients with } \\
\text { polymyalgia }\end{array}$ & $\begin{array}{l}\text { Patients with } \\
\text { rheumatoid } \\
\text { arthritis }\end{array}$ \\
\hline \multicolumn{3}{|l|}{ Age (yrs) } \\
\hline Mean (range) & $65(44-80)$ & $59(39-79)$ \\
\hline \multicolumn{3}{|l|}{ Sex } \\
\hline Male & 7 & 4 \\
\hline Female & 13 & 9 \\
\hline \multicolumn{3}{|l|}{ Steroids } \\
\hline Treatment (mg) & 16 & 7 \\
\hline Mean (range) & $14(4-20)$ & $5(3-10)$ \\
\hline \multicolumn{3}{|l|}{ Duration of disease (m) } \\
\hline Mean (range) & $13(1-34)$ & $7(3-15)$ \\
\hline \multicolumn{3}{|l|}{ Activity of disease } \\
\hline Active & 11 & 8 \\
\hline Inactive & 9 & 5 \\
\hline \multicolumn{3}{|l|}{ Temporal artery biopsy } \\
\hline +ve & 10 & 一 \\
\hline$-v e$ & 2 & - \\
\hline Not attempted & 8 & 13 \\
\hline
\end{tabular}

were studied; in most the diagnosis was made clinically, in only twelve was a temporal artery biopsy obtained. Lymphocytes were obtained from four patients before treatment with steroids. The remainder had been on steroids for periods varying from one week to 20 months. These patients showed considerable variation in their clinical activity (see Table I). Three of the four patients who were tested before treatment were subsequently tested while on steroids.

Thirteen patients with rheumatoid arthritis were studied (Table I), seven were taking steroids when tested and two had vasculitis. Control groups included eight healthy people, seven patients with osteoarthritis, and four patients with unrelated disorders. Three patients with polyarteritis, in whom the diagnosis had been confirmed by arterial biopsy, were examined. Thirteen patients with polymyositis were studied and in all the diagnosis had been confirmed by muscle biopsy, all were receiving steroids, and four were clinically active.

\section{LYMPHOCYTE CULTURE}

Peripheral blood, 25-30 ml, was collected from each subject and defibrinated in a sterile plastic bottle by shaking with sterile glass beads for $10 \mathrm{~min}$. The blood was then mixed with an equal volume of $3 \%$ gelatine in normal saline, and allowed to stand in a plastic syringe for 20-30 min to effect sedimentation of erythrocytes. The supernatant mixture was expelled into a sterile bottle, and the sedimentation procedure repeated. The resulting mixture of gelatine, serum, and white blood cells was spun at $400 \mathrm{~g}$ for $10 \mathrm{~min}$ at room temperature, the supernatant discarded, and the white cells washed in Eagle's minimum essential medium (MEM). They were then resuspended in MEM plus $10 \%$ fetal bovine serum (Biocult, lot 000078) and antibiotics (penicillin 200 units $/ \mathrm{ml}$ and streptomycin $100 \mu \mathrm{g} / \mathrm{ml}$ ). The number of small mononuclear cells in this leucocyte-rich suspension was counted and the volume adjusted to give a concentration of 2 million lymphocytes $/ \mathrm{ml}$. The lymphocyte suspension $(0.5 \mathrm{ml})$ was then added to each sterile plastic culture tube containing an equal volume of medium in which the antigen was diluted, or containing medium alone. Positive control cultures were set up by adding lymphocytes to tubes containing phytohaemagglutinin (PHA) (Wellcome, lot K4416) as mitogen in final concentration of 3 parts PHA to 1000 parts medium. All cultures were set up in triplicate.

\section{ANTIGEN}

The antigen used was a $20 \% \mathrm{w} / \mathrm{v}$ homogenate of human artery obtained either at post mortem, or from patients at arterial surgery, or from a temporal artery biopsy. The artery was placed in a sterile Petri dish, finely diced with a scalpel blade, and then homogenized in MEM using a Sylversen blender. Aliquots of the antigen were stored at $-20^{\circ} \mathrm{C}$ and used for up to 4 weeks from preparation. Muscle antigen was obtained at the time of total hip replacement on patients with osteoarthrosis and was prepared in a similar manner. The antigens were used in a wide range of dilutions for each experiment and at each dilution three culture tubes were set up.

MEASUREMENT OF DNA SYNTHESIS

Lymphocyte cultures were incubated at $37^{\circ} \mathrm{C}$ for 5 days in the case of cultures containing muscle and arterial antigen, and 3 days in the case of PHA cultures. For the last $18 \mathrm{~h}$ of incubation $1 \mu \mathrm{Ci}$ of tritiated thymidine at $150 \mathrm{mCi} / \mathrm{mmol}$ was added to each tube. This quantity of thymidine is sufficient to saturate at least $90 \%$ of the intrinsic thymidine synthesis over the pulse period. At the end of the incubation period $2 \%$ acetic acid in normal saline was added to lyse red cells, and the tubes were then spun at $1000 \mathrm{~g}$ for $10 \mathrm{~min}$ at $4^{\circ} \mathrm{C}$. The cells were then washed twice with $5 \%$ trichloracetic acid, spun, and washed with absolute alcohol, and the final residue allowed to dry. To redissolve the precipitated DNA, $0.3 \mathrm{ml} 0.1 \mathrm{~N}$ sodium hydroxide was added and a $0.2 \mathrm{ml}$ aliquot of this solute was added to $10 \mathrm{ml}$ scintillation fluid in polyethylene vials. The activity in each sample was assessed in a Beckman Coincidence liquid scintillation counter. Background and quench corrections were made.

The average number of counts per minute (cpm) obtained in the case of lymphocytes cultured in the presence of antigen at each dilution was determined and from this the average cpm obtained in cultures with medium only were subtracted. This gave a figure that was considered to represent the degree of stimulation or inhibition of DNA synthesis in lymphocytes produced by the antigen at each dilution.

\section{STATISTICS}

The statistical differences between groups was assessed by the Wilcoxon two group nonparametric ranking test.

\section{Results}

STIMULATION TO ARTERY ANTIGEN

The mitotic response from patients with polymyalgia rheumatica varied with the concentration of antigen used. This is shown in Fig. 1. With the highest concentration of antigen used $(1: 10)$, the rate of DNA synthesis tended to be lower than the spontaneous rate. Maximum stimulation occurred 


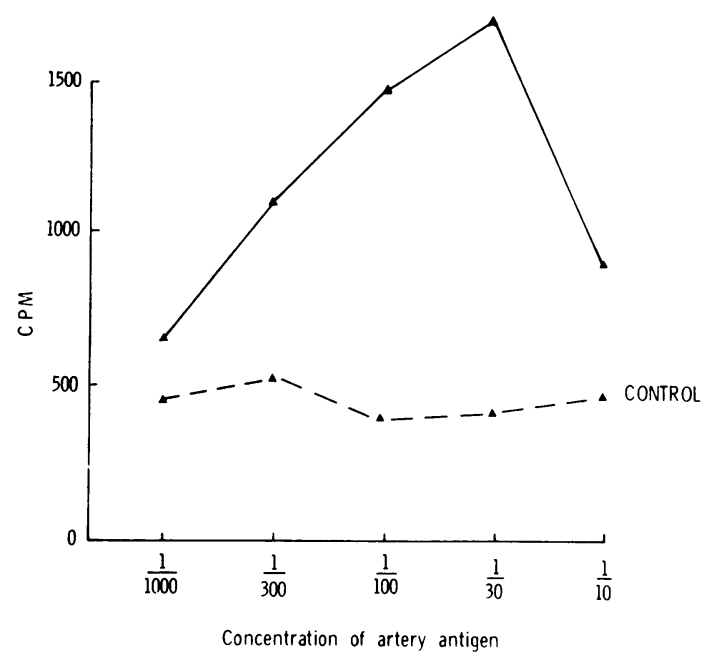

FIG. 1 Variation in transformation with antigen concentration

generally between the $1: 30$ and $1: 100$ dilution of antigen. The results are expressed as the difference between the maximum thymidine uptake with antigen and the spontaneous uptake without antigen.

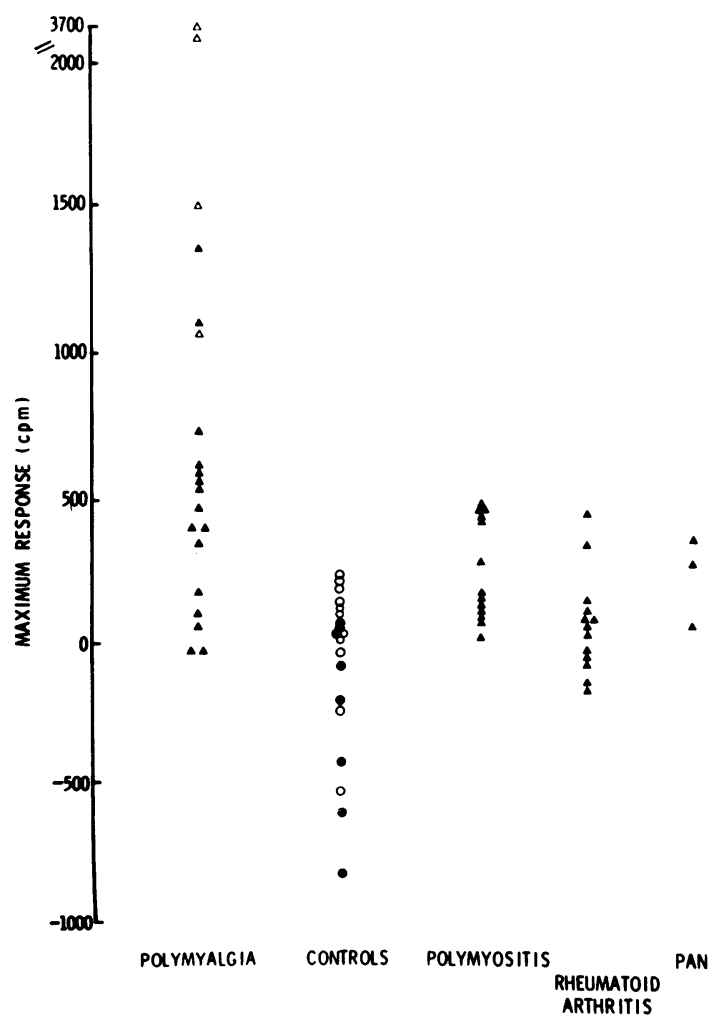

FIG. 2 Maximum transformation responses in various diseases: artery as antigen. Untreated $\Delta$, healthy $\bullet$, unrelated disease 0
The results of stimulation with artery antigen in all groups are shown in Fig. 2. Marked stimulation was seen in clinically active cases of polymyalgia while inactive cases showed little or no increase above controls (Fig. 3). Treatment did not prevent a response in patients with active disease, although active untreated patients generally showed higher thymidine uptake than active treated patients (Table IV).

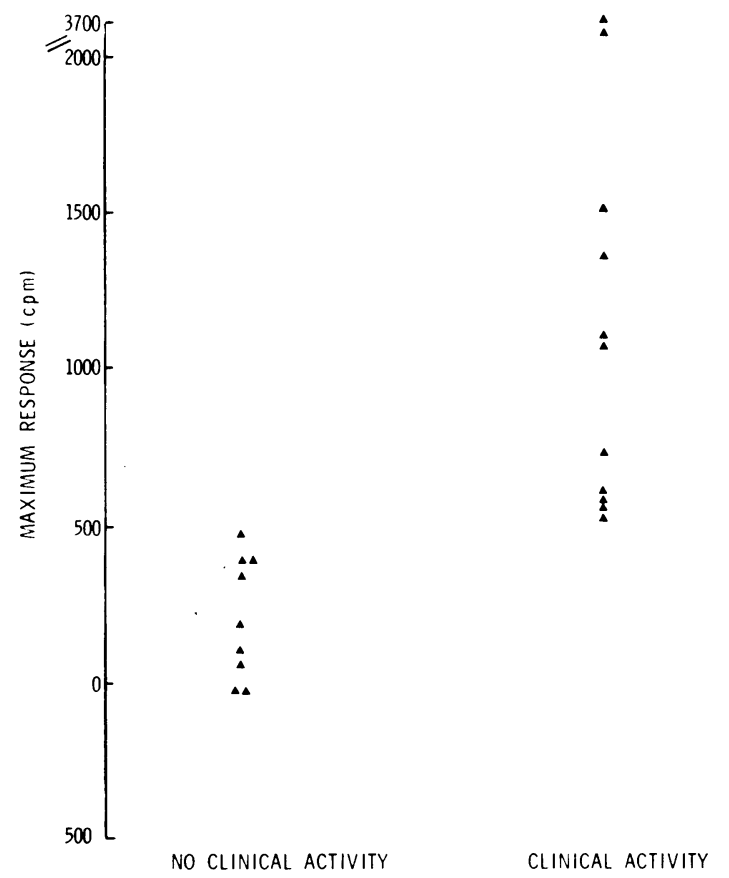

FIG. 3 Artery as antigen: transformation and clinical activity

A striking observation is that clinically active cases of polymyalgia showed no overlap in their response with the polymyositis patients despite good responses by the clinically active patients with polymyositis to muscle antigen. This contrasts markedly with the response in both polymyalgia and polymyositic patients to muscle antigen (see below).

The significance of the differences in response to artery antigen between the various groups and subgroups is tabulated in Table II.

STIMULATION TO MUSCLE ANTIGEN

Transformation to muscle antigen has been described by us previously (Esiri and others, 1973). The results obtained in this study with muscle antigen are shown in Fig. 4. These results did not differ significantly from those reported in our previous study (Table III). This indicates that the assay is quantitatively reproducible over time, as the studies were run sequentially 
Table II Significance levels for differences between groups in response to antigens

\begin{tabular}{|c|c|c|c|}
\hline \multicolumn{2}{|l|}{ Groups compared } & \multirow[t]{2}{*}{ Muscle antigen } & \multirow[t]{2}{*}{ Arterial antigen } \\
\hline$A$ & $B$ & & \\
\hline $\begin{array}{l}\text { Active polymyalgia } \\
\text { Active polymyalgia } \\
\text { All polymyalgia } \\
\text { All polymyalgia } \\
\text { All polymyalgia } \\
\text { Active polymyositis } \\
\text { All polymyositis } \\
\text { All polymyositis } \\
\text { Rheumatoid arthritis }\end{array}$ & $\begin{array}{l}\text { Active polymyositis } \\
\text { Inactive polymyalgia } \\
\text { All polymyositis } \\
\text { All controls } \\
\text { Rheumatoid arthritis } \\
\text { Inactive polymyositis } \\
\text { All controls } \\
\text { Rheumatoid arthritis } \\
\text { All controls }\end{array}$ & $\begin{array}{l}\text { A }<\text { B P }<0.05 \\
\text { A }>\text { B P }<0.01 \\
\text { A }<\text { B N } \\
\text { A }>\text { B }<0.005 \\
\text { A }>\text { B }<0.05 \\
\text { A }>\text { B P }<0.005 \\
\text { A }>\text { B P }<0.0125 \\
\text { A }>\text { B P }<0.005 \\
\text { A }>\text { B NS }\end{array}$ & $\begin{array}{l}\text { A }>\text { B P }<0.0025 \\
\text { A }>\text { B P }<0.0005 \\
\text { A }>\text { B P }<0.05 \\
\text { A }>\text { B P }<0.0005 \\
\text { A }>\text { B P }<0.0005 \\
\text { A }>\text { B NS } \\
\text { A }>\text { B P }<0.005 \\
\text { A }>\text { B P }<0.0125 \\
\text { A }>\text { B NS }\end{array}$ \\
\hline
\end{tabular}

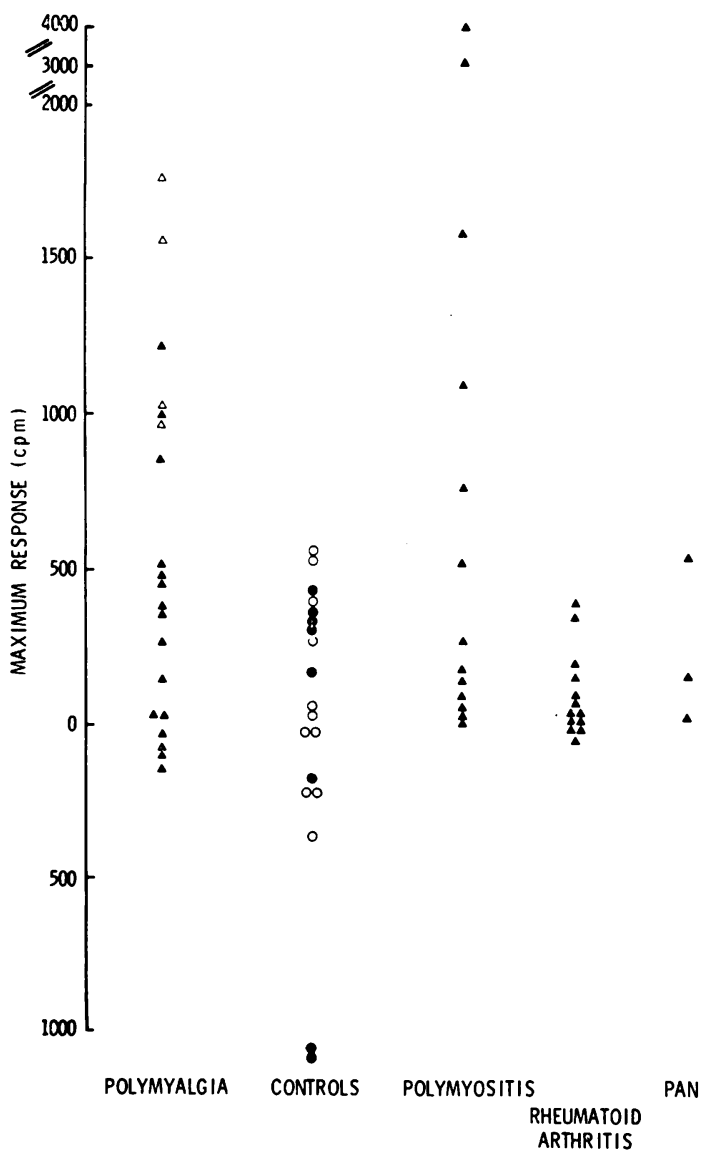

FIG. 4 Maximum transformation responses in various diseases: muscle as antigen. Untreated $\triangle$, healthy $\bullet$, unrelated disease 0

Table III Differences in response to antigen: previous and current study

\begin{tabular}{|c|c|c|c|}
\hline & Previous & Current & $x^{2}$ \\
\hline $\begin{array}{l}\text { Polymyositis } \\
\text { Polymyalgia rheumatica }\end{array}$ & $\begin{array}{l}22 \\
20\end{array}$ & $\begin{array}{l}14 \\
18\end{array}$ & $\begin{array}{l}0 \cdot 20 \\
0 \cdot 28\end{array}$ \\
\hline
\end{tabular}

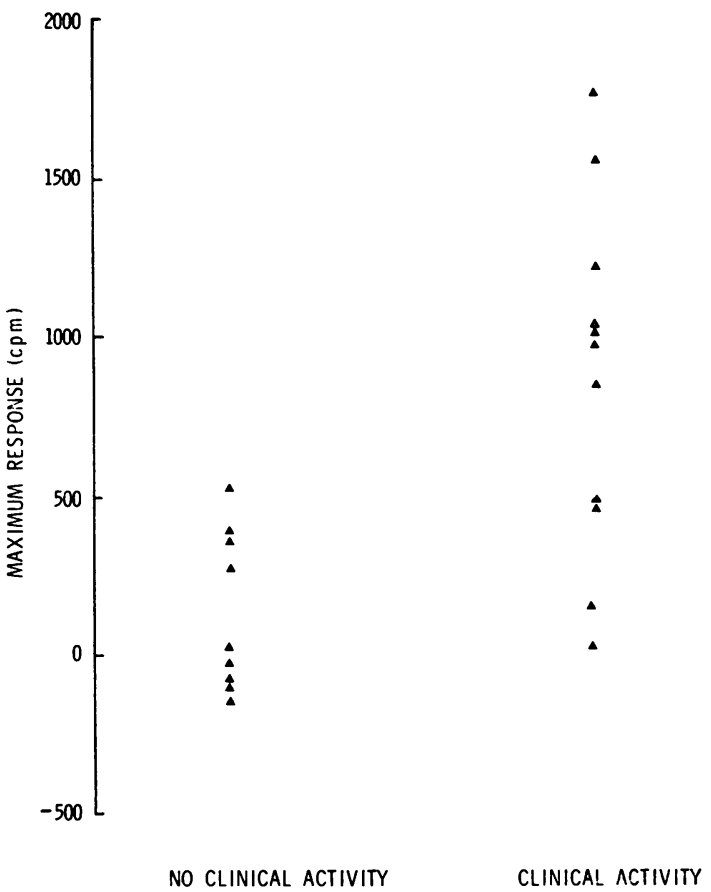

FIG. 5 Muscle as antigen: transformation and clinical activity

rather than concurrently. The response in polymyalgia showed variation related to clinical activity (Fig. 5).

\section{DIFFERENCE BETWEEN RESPONSE TO ARTERY AND MUSCLE ANTIGEN}

The differences between the response to the two antigens was only significant in one group-the active polymyositics (see Table IV). This result strongly suggests that the antigen(s) in arteries which stimulates the polymyalgia patients is (are) distinct from that (those) in muscle antigen which induces transformation in polymyositis. 
Table IV Difference between stimulation to artery and muscle antigen

\begin{tabular}{|c|c|c|c|c|}
\hline & \multicolumn{3}{|c|}{$\begin{array}{l}\text { Counts attributable to } \\
\text { stimulation }\end{array}$} & \multirow{2}{*}{$\begin{array}{l}\text { Daily steroid } \\
\text { treatment } \\
\text { at testing ( } m g \\
\text { prednisone) }\end{array}$} \\
\hline & $\begin{array}{l}\text { Muscle } \\
\text { antigen }\end{array}$ & & $\begin{array}{l}\text { Artery } \\
\text { antigen }\end{array}$ & \\
\hline \multicolumn{5}{|c|}{ Active } \\
\hline polymyalgia & 1002 & & 1084 & 15 \\
\hline & $\begin{array}{l}497 \\
947\end{array}$ & & $\begin{array}{r}602 \\
1502\end{array}$ & 15 \\
\hline & $\begin{array}{r}942 \\
1204\end{array}$ & & 1371 & $7 \cdot 5$ \\
\hline & 469 & & 3710 & - \\
\hline & 1008 & & 745 & 5 \\
\hline & 1560 & & 3116 & - \\
\hline & 1761 & & 1057 & - \\
\hline & Muscle & $<$ & Artery NS & \\
\hline \multicolumn{5}{|l|}{ Active } \\
\hline polymyositis & $\begin{array}{r}4347 \\
3146\end{array}$ & & 495 & 30 \\
\hline & 1590 & & 441 & 15 \\
\hline & 1027 & & 501 & 40 \\
\hline & Muscle & $>$ & $\begin{array}{l}\text { Artery } \\
\quad P<0.05\end{array}$ & \\
\hline
\end{tabular}

\section{Discussion}

A significantly increased rate of transformation in the presence of muscle has previously been shown in lymphocytes from patients with polymyositis and polymyalgia rheumatica (Esiri and others, 1973). Results of further experiments reported here have shown an increased rate of transformation in the presence of artery by lymphocytes from patients with polymyalgia, with only a marginal response in patients with polymyositis. These results support the suggestion that the sensitizing antigen in polymyalgia in the skeletal muscle homogenate resides in the vascular tissue, but could also be explained by the coexistence of two antigens in muscle both of which are distinct from the artery antigen to which polymyalgia patients are sensitive.

The possibility that the increased transformation rates obtained were due to the presence of transplantation antigens in the arterial homogenate is discounted first by the finding of increased responses in lymphocytes from patients when tested with antigen prepared from their own artery, and secondly by the absence of a positive response in lymphocytes from the great majority of control subjects when cultured with allogenic muscle.

These findings are of interest in view of reports emphasizing the common occurrence of giant cell arteritis in patients with polymyalgia rheumatica (Alestig and Barr, 1963; Fauchald and others, 1972). The antigens responsible for producing the increased transformation are not known. It is tempting to suggest that they are present in the internal elastic lamina as there are several studies which suggest that these fibres are initially involved in the disease process, and it has been suggested that it is here that the disease originates (Kimmelstiel, Gilmour, and Hodges, 1952). There is initial swelling and fragmentation, then a surrounding granulomatous reaction (Harrison, 1948; Smith, 1969). Histological changes have been described in temporal arteries in association with advancing age (Kimmelstiel and others, 1952). They involve mainly the intima and internal elastic lamina and differ only $\vec{\circ}$ in degree from those encountered in temporal arteritis, but there is never an inflammatory cell $\stackrel{\sigma}{\omega}$ infiltrate unless in relation to large atheromatous plaques. Attempts to investigate the immunological properties of elastin in this disease have been made (Balmforth, 1964), but there were difficulties in obtaining a satisfactory antigen. Although there is a $\vec{N}$ high incidence of involvement of the head and neck vessels in temporal arteritis, the intracranial arteries are seldom involved (Heptinstall, Porter and Barkley, $\vec{D}$ 1954; Crompton, 1959; Kjeldsen and Reske- O Nielsen, 1968). Wilkinson and Russell (1972) studied post-mortem material and suggested that there was a close correlation between the susceptibility to $V$ arteritis and the amount of elastic tissue present in the arterial wall. Maybe temporal arteritis arises as an immune reaction to the internal elastic lamina which has been damaged with advancing age. This would explain the late onset of the disease in patients not obviously disposed to autoimmune disease, and $\overline{\vec{z}}$ would explain the main histological features and the suppressive effects of corticosteroid therapy.

Clinically, there is no clear distinction between temporal arteritis and polymyalgia rheumatica. The clinical picture of polymyalgia rheumatica is very variable (Mowat and Hazleman, 1974), and overt temporal or other arterial vasculitis may be present to aid diagnosis. However, the arteritis is not uniform and the small section of temporal artery at biopsy may well be normal. For this reason, 을 corticosteroid therapy should be started when $\frac{T}{0}$ polymyalgia rheumatica has been diagnosed in order to prevent ocular complications. Polymyalgia o rheumatica is a diagnosis made by exclusion of other disease states. There is often considerable delay 0 before these patients are referred for investigation $\omega$ and treatment (Mowat and Hazleman, 1974). This causes the patient unnecessary suffering and may re- $\stackrel{0}{C}$ sult in vascular lesions. It is suggested that estimation $\mathbb{D}$ of lymphocyte transformation to artery as antigen may prove to be of considerable use as a positive diagnostic aid in this condition.

We thank the physicans of the United Oxford Hospitals and Drs. A. Hill, A. Mowat, and D. Triger, and Professor R. Wright for allowing us to study patients under their $\bigcirc$ care. We should like to thank Dr. A. Mowat for his helpful advice throughout this study. 


\section{References}

Alestig, K., AND BARR, J. (1963) Lancet, 1, 1228 (Giant-cell arteritis: a biopsy study of polymyalgia rheumatica, including one case of Takayasu's disease)

Andrews, F. M. (1966) 'Polymyalgia rheumatica', in 'Modern Trends in Rheumatology', ed. A. G. S. Hill, vol. 1, p. 362. Butterworths, London

BALMforth, G. V. (1964) M.D. Thesis. University of London (Temporal arteritis: a clinical and latoratory study)

Brooke, M. H., and Kaplan, H. (1972) Arch. Path., 94, 101 (Muscle pathology in rheumatoid arthritis, polymyalgia rheumatica and polymyositis. A histochemical study)

Bruk, M. (1967) Ann. rheum. Dis., 26, 103 (Articular and vascular manifestations of polymyalgia rheumatica)

Chalmers, T. M., Alexander, W. R. M., and Duthie, J. J. R. (1964) Ibid., 23, 123 (Polymyalgia: problems of differential diagnosis)

CRompton, M. R. (1959) Brain, 82, 377 (The visual changes in temporal (giant-cell) arteritis. Report of a case with biopsy findings)

Esiri, M. M., Maclennan, I. C. M., and Hazleman, B. L. (1973) Clin. exp. Immunol., 14, 25 (Lymphocyte sensitivity to skeletal muscle in patients with polymyositis and other disorders)

Fauchald, P., Rygvold, O., AND Oystese, B. (1972) Ann. intern. Med., 77, 845 (Temporal arteritis and polymyalgia rheumatica. Clinical and biopsy findings)

Hamilton, C. R., Shelley, W. M., and Tumulty, P. A. (1971) Medicine, 50, 1 (Giant-cell arteritis: including temporal arteritis and polymyalgia rheumatica)

HAMrin, B. , JonsSON, N., AND LANDBERG, T. (1965) Lancet, 1, 1193 (Involvement of large vessels in polymyalgia arteritica)

Harrison, C. V. (1948) J. clin. Path., 1, 197 (Giant-cell or temporal arteritis. A review)

Heptinstall, R. H., Porter, K. A., AND Barkley, H. (1954) J. path. Bact., 67, 507 (Giant-cell (temporal) arteritis)

Hunder, G. G., Disney, T. F., ANd Ward, L. E. (1969) Mayo Clin. Proc., 44, 849 (Polymyalgia rheumatica)

-, AND ShEPS, S. G. (1967) Arch. intern. Med., 119, 638 (Intermittent claudication and polymyalgia rheumatica. Association with panarteritis)

Kimmelstiel, P., Gilmour, M. T., ANd Hodges, H. H. (1952) Arch. Path., 54, 157 (Degeneration of elastic fibres in granulomatous giant cell arteritis (temporal arteritis))

Kueldsen, M. H., and Reske-Nielsen, E. (1968) Acta Ophthal., 46, 49 (Pathological changes of the central nervous system in giant-cell arteritis)

Mowat, A. G., AND Hazleman, B. L. (1974) J. Rheum., 1, 190 (Polymyalgia rheumatica. A clinical study with particular reference to arterial disease)

Saunders, M., Knowles, M., ANd Currie, S. (1969) J. Neurol. Neurosurg. Psychiat., 32, 569 (Lymphocyte stimulation with muscle homogenate in polymyositis and other muscle-wasting disorders)

SмITH, K. R. (1969) Ibid., 32, 348 (Electron microscopy of giant-cell (temporal) arteritis)

Wilkinson, I. M. S., AND Russell, R. W. R. (1972) Arch. Neurol., 27, 378 (Arteries of the head and neck in giant cell arteritis) 